\title{
BETTER REGULATION FOR GROWTH
} GOVERNANCE FRAMEWORKS AND TOOLS FOR EFFECTIVE REGULATORY REFORM 
(C)2010 The World Bank Group

1818 H Street NW

Washington DC 20433

Telephone: 202-473-1000

Internet: www.worldbank.org

All rights reserved

Rights and Permissions

The material in this publication is copyrighted. Copying and/or transmitting portions or all of this work without permission may be a violation of applicable law. The World Bank encourages dissemination of its work and will normally grant permission to reproduce portions of the work promptly.

For permission to photocopy or reprint any part of this work, please send a request with complete information to the Copyright Clearance Center Inc., 222 Rosewood Drive, Danvers, MA 01923, USA; telephone: 978-750-8400; fax: 978-750-4470; Internet: www.copyright.com.

All other queries on rights and licenses, including subsidiary rights, should be addressed to the Office of the Publisher, The World Bank Group, 1818 H Street NW, Washington, DC 20433, USA; fax: 202-522-2422; e-mail: pubrights@worldbank.org.

\section{About the Investment Climate Advisory Services of the World Bank Group}

The Investment Climate Advisory Services (IC) of the World Bank Group helps governments implement reforms to improve their business environment, and encourage and retain investment, thus fostering competitive markets, growth and job creation. Funding is provided by the World Bank Group (International Finance Corporation-IFC, the Multilateral Investment Guarantee AgencyMIGA, and the World Bank) and over 15 donor partners working through the multi-donor FIAS platform.

The findings, interpretations and conclusions included in this note are those of the author and do not necessarily reflect the view of the executive directors of the World Bank Group or the governments they represent.

\section{Better Regulation for Growth Program}

The Better Regulation for Growth (BRG) Program was launched in 2007 by the Dutch Ministry of Foreign Affairs, the UK Department for International Development (DFID) and the IC of the World Bank Group.

The objective of the BRG Program is to review and synthesize experiences with regulatory governance initiatives in developing countries, and to develop and disseminate practical tools and guidance that will help developing countries design and implement effective regulatory reform programs. Reports and other documentation developed under the BRG Program are available at: www .ifc.org/brg 


\title{
Table of Contents
}

\author{
Acknowledgments ........................................................................................... v \\ Executive Summary ................................................................................. vi \\ Introduction ....................................................................................................... 1 \\ Regulatory Quality and Competition Policy: Key Concepts, \\ Definitions and Relationships ................................................................... 3

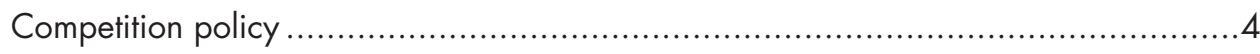 \\ Linking regulatory quality and competition policy .....................................6
}

Institutions and Processes for Implementing Regulatory

Quality and Competition Policy Agendas................................................ 8

Roles of regulatory reform and competition authorities - key similarities

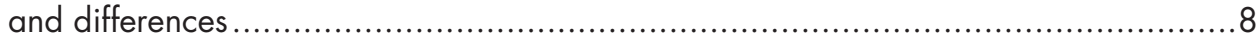

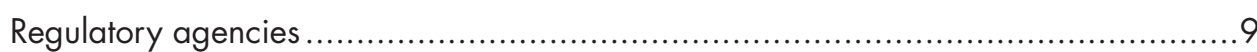

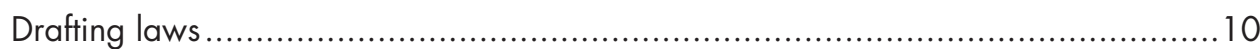

Consultation with stakeholders and the community .................................. 10

The decision-making process within government......................................... 11

Use of legislation and framework rules................................................... 12

When is Competition Assessment Important? ...................................... 13

Test 1) Limiting the number or range of suppliers ......................................... 13

Test 2) Limiting ability of suppliers to compete ............................................ 14

Test 3) Reducing incentives of suppliers to compete vigorously .......................... 14

Mechanisms for Coordinating Competition Policy and

Regulatory Quality Assessments .............................................................. 16

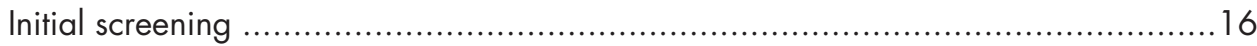

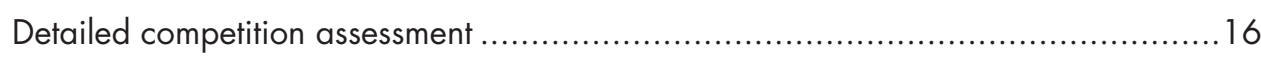

Review of competition assessment .............................................................. 17

Advice to decision makers...................................................................... 18

Post-implementation review................................................................ 18

Applying competition policy and RIA assessments in developing countries ............. 18

Appendix 1: Options for Addressing Regulatory Restrictions ............... 22

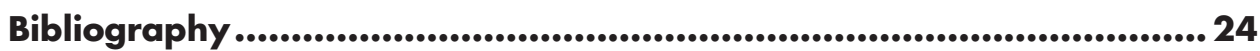

Annex: Better Regulation for Growth Program ..................................... 26 


\section{List of Boxes}

Box 1: Regulatory Impact Assessment ............................................... 4

Box 2: Potential Interactions - Regulations and Competition Policy ..........................5

Box 3: Benefits of Using Competition Policy.................................................. 7

Box 4: Institutional Responsibilities in the United Kingdom ............................. 10

Box 5: Strengthening Competitiveness in Mexico .............................................. 11

Box 6: Ensuring Effective Screening of Regulations ........................................ 17

Box 7: Competition Policy, Regulation-Costa Rican Rice Sector ........................... 19

Box 8: Integrating Competition Policy and RIA in Australia...................................20

Box 9: Integrating Regulation Assessments .................................................20 


\section{ACKNOWLEDGMENTS}

The report has been prepared by Stephen Rimmer, Senior Regulatory Reform Expert at the Investment Climate Department of the World Bank Group.

An early draft of this document was discussed at the Technical Meeting of the Advisory Panel of the Better Regulation for Growth Program held in The Hague on November 13-14, 2008. Comments to this draft were provided by participants to this meeting: Andre Nijsen, Andreja Marusic, Andrea Renda, Claudio Radaelli, Colin Kirkpatrick, Delia
Rodrigo, Edward Donelan, Esra Yilmaz, Eva Buitenkamp, Fabrizio de Francesco, Greg Bounds, Jeroen Nijland, Josephine Kanyi, Ksenija Vidulic, Lars Grava, Margo Thomas, Mustafizur Rahman, Nick Godfrey, Richard Sandall, Stephen Rimmer, Scott Jacobs and Ulrich Ernst.

Early and advanced drafts of the report benefited from additional comments from Rex DeightonSmith, Richard Sandall and Sutapa Choudhury. Zai Fanai supported the publication of the report. 


\section{EXECUTIVE SUMMARY}

Regulatory reform and competition policy are two important and inter-related areas of regulatory policy and public administration. Both can play a key role in improving the quality of regulations, thus creating healthy and competitive markets and an attractive investment climate, which in turn leads to greater economic growth, employment and incomes.

Governments in both developed and developing countries are increasingly adopting explicit policies and strategies to improve regulatory quality. But achieving such high-quality regulations is not an easy task:

Regulation is a complex balancing act between advancing the interests of consumers, competitors and investors, while promoting a wider public interest' agenda (Parker, 2001).

A growing number of countries, over 100 at the present time, have explicit competition policies, although many of these are not comprehensive and do not cover some key elements of competition policy. In addition, around 70 countries have processes in place (or are establishing) processes to improve the quality of new and amended regulations. These relatively recent trends have resulted in a growing number of policymakers - in both developed and emerging countries - having to consider how to best integrate competition policy and regulatory reform tools, approaches, and institutions. Indeed, it is best to think through these issues while these processes are being established in a large number of countries, rather than trying to fix problems resulting from poor integration after competition policy and regulatory quality processes are already in place and operating.

A range of tools and approaches are available to reform regulations. These include tools for reviewing the stock of existing regulations (such as process re-engineering, staged repeal, regulatory guillotine, sunsetting and Standard Cost Model). A range of tools are also available for improving the quality of the flow of new or amended regulations (including public consultation and hearings, forward planning of reviews, regulatory performance indicators and regulatory impact assessment (RIA). These tools are described in 
detail in the BRG paper, "Tools and Approaches to Review Existing Regulations."

It is important to note that RIA is only one tool for improving the quality, effectiveness and transparency of new regulations. That said, RIA is employed in 90 per cent of OECD countries, with over 20 developing (low and middle income) countries also using RIA (such as Mexico, Serbia, Bulgaria, Tanzania, South Africa and Uganda). Several other developing countries have started to establish RIA or are actively considering implementing this process (such as Turkey, Bangladesh, Uzbekistan, Vietnam, Egypt, Indonesia, Cambodia, Brazil and Kenya).

In many countries, individual regulatory agencies, including competition agencies, use key elements of RIA when reviewing and reforming regulations. RIA is essentially a way of thinking through regulatory issues. This approach typically involves a central area of government providing a quality assurance role for new or amended regulations. In addition, RIA is usually prepared by regulatory agencies and aims to improve the quality of information provided to decision makers. A detailed description and discussion of RIA is provided in the BRG paper, "Making it Work: RIA Light for Transition and Developing Countries."

Competition policy is also widely used and is applied in over 100 countries. It focuses on protecting and promoting effective competition by addressing anticompetitive business practices and government policies and regulations that unnecessarily impede the competitive process. It also focuses on establishing pro-competitive regulations which underpin the operation of healthy and competitive markets. Competition policy, which is usually implemented thought government policy statements and associated laws, aims at fostering an environment where businesses have incentives to invest, innovate and offer the widest possible choice of goods and services at low prices. Competition policy can be applied at the national and sub-national levels of government.
Competition policy can play a very important role in safeguarding the interests of consumers vis-a-vis powerful and well-connected businesses. Indeed, without competition policy, consumers and small producers in a wide range of markets, such as agricultural produce, telecommunications, energy, water and transport, will typically be disadvantaged by being charged excessive prices or being paid below market prices for goods and services they produce. These outcomes can be caused by - and generate - additional corruption. They also impact adversely on the poorest and most vulnerable sections of society, as was the case with the rice sector in Costa Rica when in 2002 the government established a statutory rice monopoly (see Box 7). Several studies have also documented the significant economic benefits of applying competition policy. For example, in Australia its use is estimated to have increased GDP by 2.5 percent, while application of antitrust measures, which are only one component of competition policy, is estimated to have generated in a range of countries a welfare gain of around 1 percent of GDP.

It is important to note that the use of competition policy in developing countries is limited, as is information about its use. For example, it is important to recognize that undertaking one aspect of competition policy, competition policy assessments, can be technically challenging, difficult to apply in some developing country contexts, and sometimes poorly documented. Therefore, this paper does not provide a wide-ranging or comprehensive review of the various elements of competition policy as they are applied in developing countries. It does not focus on the broader uses of competition policy in developing countries - including the important area of establishing viable independent competition agencies. Nor does it focus on administering and applying competition policy, including competition tests and checklists. The literature on these issues is robust and freely available, including through the International Competition Network (ICN). Rather, this paper focuses specifically on the links between competition 
policy and the commonly used RIA reform tool, identifies examples of its use by developing countries, and provides a basis for more detailed and wide-ranging research and dialogue.

As noted above, this paper focuses on competition policy and RIA because both approaches are interrelated and increasingly important aspects of regulatory governance, policymaking and administration in developing countries. Furthermore, there is potential overlap and interaction between these two areas of activity. Indeed, both seek to improve the regulatory environment and system, but use different approaches and tools, and usually involve separate institutions. If this overlap is not well managed there is a risk that regulatory policy and administration could become unnecessarily confused, ineffective or inefficient, thus undermining the investment climate. Key questions include how this overlap between competition policy and RIA can be best avoided and how these two approaches can be well integrated and coordinated. For example, should there be one institution performing both roles, or should they be separate? How can RIA be consistent and aligned with competition policy assessments, guidelines and tests? Furthermore, how can regulatory reform and competition policy be applied so that they are mutually reinforcing and support each other?

The key nexus of the overlap and synergies are within these two processes of regulation making embedded in a regulatory quality control system. For example, the RIA provides a framework for balancing a range of competing public policy objectives, including efficiency, consumer protection, environmental and climate protection and social equity. There are a range of specific approaches and options for integrating considerations of pro-competitive regulation in regulatory quality control processes such as RIA. The synergies between competition policy and RIA are primarily in terms of integration of the regulatory policy-making process, and less so in terms of institutional integration. Indeed, on balance, the structural separation of regulatory reform bodies and competition policy regulators appears to be the most desirable and beneficial institutional setting.

Indeed, competition and regulatory reform authorities typically operate as separate areas of government since they perform different roles. Competition policy authorities usually administer and enforce competition policy and related laws, while regulatory reform bodies oversee government regulation review and reform. Both areas of government usually have a relatively high level of independence from the executive arm of government. They also have other similarities, such as performing advocacy roles to promote regulatory quality, training for officials developing and applying regulations, assessing and commenting on regulatory proposals and research, and commenting on regulatory issues. There is clear scope for both types of agencies to retain their unique and important roles, while also exchanging views about regulatory issues and proposals. Such consultation does not undermine in any way their respective independence or roles. Indeed, such cooperation and coordination is evident in various countries, including Mexico and Australia.

Furthermore, such cooperation and coordination by competition policy and regulatory quality agencies can occur throughout the policy development process. This includes:

- Through initial screening tests and requirements administered and disseminated by the regulatory reform body as part of the guidelines on the conduct of RIA. The competition and regulatory reform authorities should consult on the development of these guidelines to ensure that competition assessment is effectively integrated with RIA and that the guidelines are consistent with competition policy and enforcement activity generally. The competition authority should provide more detailed guidance material for the use of regulators where appropriate. A significant proportion of new regulation can have competition and regulatory quality implications, 
including business licenses, sector specific regulation in agricultural, transport, telecommunication, energy and water sectors, and in allocating rights to scarce resources such as mining and fisheries.

- Where screening indicates that a more detailed competition assessment is needed, this is unlikely to be within the capabilities of the regulatory agency to undertake this assessment. Assistance from the competition authority (or, where feasible, other sources of expert advice on competition issues) is very important at this point.

- In many countries with RIA processes the regulatory reform authority reviews the RIA document and provides advice on its adequacy. The competition assessment should be considered as part of this process where the regulatory issues under consideration have competition policy impacts or implications. ${ }^{1}$ Where major competition issues are involved, the regulatory reform authority should be required to consult with the competition authority. This will ensure that appropriate expertise is available and that a consistent approach is taken to competition issues.

- When concerns raised by the competition and/or regulatory reform authorities have not been dealt with adequately by the regulator, these bodies should have the responsibilityand the opportunity-to raise these concerns with decision-makers.

- Many of the impacts of competition-restricting regulations are either unforeseen or difficult to gauge accurately before a regulation is implemented. A post-implementation review can be undertaken whenever a regulation with a

1 The term "competition assessment" in this paper denotes the identification and assessment of competition-related issues as part of the policy development process. It does not denote assessments carried out purely to enforce competition policies and laws. substantial anti-competitive impact is made. A review undertaken two or three years after a regulation is adopted can allow judgments to be made about whether the benefits expected to flow from the restriction on competition are being achieved. More importantly, it can determine whether the costs have been accurately predicted and whether unanticipated negative effects have arisen that might justify revising or withdrawing the regulation.

It is also important to note the role of all participants in regulatory systems such as government regulators, law drafting agencies and community consultation processes since each has a very important role to play in supporting and applying both regulatory quality and competition policy outcomes.

Achieving these results can be challenging, particularly in developing countries where there are low capacities. Indeed, competition policy and RIA assessment can be a demanding and highly technical process. However, such assessments can and are undertaken with limited expert resources and, therefore, are feasible even in the context of relatively low-capacity government administrations. For example, in 2008 several RIAs prepared in Moldova and Indonesia considered both regulatory quality and competition policy issues. In Moldova, RIAs focused on regulation of aspects of the energy and telecommunications sectors, and in Indonesia, they focused on the agricultural sector.

That said, it is also important to note that RIA processes are usually implemented in a sequential manner and strengthened progressively over time. Furthermore, RIAs typically focuses on a subset of regulations since it is not feasible to prepare RIAs for all new regulations. Therefore, the extent to which competition policy issues are included within RIAs will depend on several factors, such as the type of RIA process used, the type of regulations considered by RIA as well as the capacities of the country or jurisdiction applying RIA. Indeed, in many cases, a given regulatory proposal may not require preparation of RIA, but will have 
competition policy implications that should be considered by the competition authority.

The paper points to some of the implications of these findings for developing countries. Ensuring appropriate integration of competition policy concerns can be important ingredients in the design of new RIA systems, and it can help align pro-reform stakeholders so that regulatory reforms enhance the investment climate in developing countries. Therefore, key strategies for applying and developing competition policy and RIA expertise in developing country contexts can include:

- using a simple screening tests that focus on identifying the most significant and important regulations;

- providing training to regulators in competition assessment and RIA;

- ensuring that competition authority and regulatory reform authorities are kept separate, but have clear, mutually supporting and independent roles; and
- providing for a cooperative approach among competition officials, regulatory quality officials, and regulators to identify possible alternatives to regulations that do not restrict competition.

Even where full competition and RIA assessments are not possible, it is important that governments use other regulatory quality control processes, such as public consultation and hearings, forward planning of reviews, regulatory performance indicators, etc., to ensure that new regulations underpin healthy competition, and where appropriate use alternative approaches to regulation that do not restrict competition. Leveraging off the role and capacities of other regulatory institutions, as described in the BRG regulatory institutions paper, is also important in strengthening the operation of regulatory systems and tools. Such processes and approaches can, at a minimum, ensure that policymakers are made aware of the potential harm from competition restrictions and other possible means of achieving broader community and government objectives. 


\section{INTRODUCTION}

Regulatory reform and competition policy are two important and inter-related areas of regulatory policy and public administration. Both can play a key role in improving the quality of regulation, and creating healthy and competitive markets and an attractive investment climate. This in turn leads to greater economic growth, employment and incomes.

Over 100 countries apply competition policy although many don't apply the policy in a comprehensive manner, nor do they cover some key elements of such policy. Furthermore, most countries apply regulatory reform strategies and around 70 use (or are establishing) RIA processes. Both competition policy and RIA approaches aim to improve and strengthen regulatory systems and the quality of regulations.

However, the interactions between these two distinct approaches have not been considered in detail in existing studies and reviews. Competition policy and RIA are inter-related and increasingly important aspects of government regulatory governance, policymaking and administration in developing countries. Furthermore, there is potential overlap and interaction between these two areas of activity. Indeed, both seek to improve the regulatory environment and system, but use different approaches and tools, and usually involve separate institutions.

If this overlap is not well managed, there is a risk that regulatory policy and administration could become unnecessarily confused, ineffective or inefficient, thus undermining the investment climate. Key questions include how this overlap between competition policy and RIA can be best avoided and how these two approaches can be well integrated and coordinated. For example, should one institution or separate institutions perform both roles? How can RIA be consistent and aligned with competition policy assessments, guidelines and tests? Furthermore, how can regulatory reform and competition policy be applied so that they are mutually reinforcing and support each other?

Part one of this paper discusses definitions and key issues associated with regulation, regulatory 
quality, and competition policy. This discussion focuses on competition policy as it relates to restrictions on competition and also pro-competitive regulation, which involves protecting consumers through economic regulation.

Part two of this paper considers institutions and processes for implementing regulatory quality and competition policy agendas, including regulatory agencies, regulatory reform bodies, competition authorities and broader regulation-making processes.
Part three notes the importance of assessing competition policy issues on a case-by-case basis and identifies the main objectives and features of competition policy. This includes a discussion about when competition policy issues are likely to play an important role in regulatory assessment and reform.

Part four considers mechanisms for coordinating - where appropriate—competition policy and regulatory quality assessments, including undertaking competition assessments and providing advice to decision makers. 


\section{REGULATORY QUALITY AND COMPETITION POLICY: KEY CONCEPTS, DEFINITIONS AND RELATIONSHIPS}

Governments in both developed and developing countries have increasingly adopted explicit policies and strategies to improve regulatory quality in recent years.

Regulation is a complex balancing act between advancing the interests of consumers, competitors and investors, while promoting a wider 'public interest' agenda (Parker, 2001).

Virtually all OECD countries now have explicit policies on regulatory quality, while a significant and increasing number of developing countries have also adopted this approach (or are currently developing policies on regulatory quality). The regulatory quality agenda recognizes that there are limits to governments' abilities to regulate in pursuit of their policy goals and that the use of regulation must be carefully managed to minimize the often unanticipated negative impacts it has on the economy and society.

High quality regulation is that which is effective in producing the desired results and efficient in achieving intended results at minimum cost.
High quality regulation also involves consultation with stakeholders and a high level of transparency during the policy development and implementation phases. The importance of these qualities of effectiveness, efficiency and transparency lies in the fact that all government action involves trade-offs between different uses of resources to achieve stated objectives and outcomes. Thus, if a key goal of policy action is to maximize social welfare, the most efficient and effective policy options should be chosen.

The goal of maximizing social welfare means that the concept of regulatory quality is fundamentally evidence-based and often relies on the principle and practice of cost-benefit and risk analysis. That is, a regulation should be adopted only if it confers benefits that are larger in total than the costs it imposes and also seeks to maximize those benefits. In undertaking such assessments, policymakers should take a broad approach to trying to identify and assess the importance of all impacts of a regulatory proposal. This embraces all things that people value, whether or not they can be expressed in monetary terms. Thus, financial, 
social, environmental, equity, sectoral and riskbased aspects of proposed regulations can all be considered, weighed and compared.

It is also important to note that regulatory governance is central to achieving the objective of good regulation. Government regulatory actions should be transparent and accountable, both to affected groups and to citizens generally. Achieving this implies ensuring that stakeholders are provided with timely opportunities to be consulted on regulatory proposals, that avenues of appeal against regulatory decisions are available, and that regulations are widely available and written in a language that allows people who must comply with them to understand them readily. A corollary of the regulatory quality concept is that policy decisions should be based on identification of a policy objective. A wide range of regulatory (and non-regulatory) means of achieving it should also be identified and their relative merits considered. Only if a conscious choice is made on the basis of an evidence-based assessment of comparative benefits, costs and risks can we be sure that the highest quality regulation has been adopted. The basic of RIA is explained in Box 1 and a detailed discussion about the use of RIA in developing countries is provided in the BRG paper, "Making it Work: 'RIA Light' for Transition and Developing Countries."

\section{Competition policy}

Competition policy is an important and powerful policy tool that focuses on the goal of protecting and promoting effective and healthy competition within markets and between markets, thereby increasing consumer and overall social economic welfare. It is based on the premise that efficient and effective markets are often the best way to achieve broader societal goals. Markets operating effectively and efficiently are characterized by healthy competition, where businesses are unable to exercise market power to the detriment of consumers. Well-functioning markets generate investment, wealth, and employment, and do not result

\section{Box 1: Regulatory Impact Assessment}

There are several widely used tools governments use to improve the quality of new or amended regulations, including public consultation and hearings, forward planning of reviews, regulatory performance indicators and RIA.

RIA refers to a process - a way of thinking through regulatory problems and issues by employing an analytical and conceptual framework - as well as preparing a document called a RIA.

There is no single approach to using RIA, which is used by both national and sub-national governments. The key elements of the RIA process include applying good practice decision-making processes that ensure accountability, transparency and use of an evidence-based approach to regulatory policy development. RIA processes are usually characterized by a central area of government providing an oversight and quality control role for new/ amended regulations.

RIA is also a document prepared to assist decision makers in determining whether, when and how to regulate. RIA documents are usually prepared for decision makers by the regulatory areas of government sponsoring new or amended regulation. RIA should identify the problem, regulatory objective of government action, identify the alternative means of achieving objectives, assess the benefits, costs and risks associated with each alternative, and provide a clear comparison of the relative merits of each option. The RIA should also identify a recommended option and discuss how it will be implemented, monitored and reviewed.

Draft RIA documents are usually made public and used as the basis for formal consultation with stakeholders and the general public, as well as being a means to provide better and more systematic information to decision makers. Final RIA documents are also often published to provide information about the reasons for regulatory decisions and to help inform implementation of new regulations. 
in significant negative spillovers (e.g. externalities). By contrast, markets will not work well when businesses (or small numbers of businesses) are able to exercise non-transitory market power to the detriment of consumers. Consumers can include other businesses purchasing inputs, households, and other consumers segments. Unnecessary regulatory restrictions on competition generate significant economic costs and can be one of the most damaging forms of regulatory intervention. Box 2 gives provide four examples on how regulation policy can interact.

Around 100 countries apply competition policies, including many developing countries such as Barbados, South Africa, Mauritius, Zambia, Uzbekistan, Jamaica and Mexico (CUTS International 2007 and Canadian International Development Research Centre 2007). However, many countries have competition policy but also employ significant exemptions that greatly undermine its effectiveness and impact (e.g., Thailand, Kenya and Morocco). Healthy and effective competition benefits the operation of the economy. In some cases it can also generate winners and losers - consumers and new businesses can often be beneficia- ries, while vested business interests with market power are often the losers. That said, when competition policies are applied, the losers from such reforms - such as labor employed by large and inefficient firms with market power - can often be compensated through mechanisms such as training and other transitional and adjustment assistance (Canadian International Development Research Centre 2007 and Hylton and Deng 2007).

Competition policy essentially has two elements. First, it entails applying various policy measures to ensure there is inter-firm rivalry and thus enhance the efficiency of markets. This involves setting market conduct rules and preventing the abuse of market power. Second, competition policy aims to ensure that regulation made in pursuit of other policy goals does not unnecessarily impede the efficient operation of markets and that, where feasible, regulation that improves market efficiency is adopted (DFID 2008). Successful competition policy requires clear policy underpinned by strong, flexible and enforceable laws, a strong and independent competition regulator, and skilled staff and related capacities (Canadian International Development Research Centre 2007).

\section{Box 2: Potential Interactions - Regulations and Competition Policy}

Regulations can contradict competition policy. Regulations may have encouraged, or even required, conduct or conditions that would otherwise be in violation of the competition policy. For example, regulations may permit price coordination, prevent advertising or other avenues of competition, or require territorial market division.

Regulations can replace competition policy. Especially where a monopoly or oligopoly appears inevitable, regulation may try to directly control specific elements of abuse of market power, through government ownership and control and/or by setting prices and controlling entry and access. Such regulation, if it has been developed and applied outside a broader competition policy and institutional context, may be inadequate to the task of preventing monopoly, the exercise of market power and protecting the interests of consumers.

Regulations can reproduce competition policy. Individual regulators may seek to prevent collusion or abuse in an industry, just as competition policy does. For example, regulations may set standards of fair competition or tendering rules to ensure competitive bidding. Different regulators may apply different standards, though, and changes in regulatory institutions may reveal that seemingly duplicate policies may have led to different outcomes.

Regulations can use competition policy methods. Instruments to achieve regulatory objectives can be designed to take advantage of market incentives and competitive dynamics. Coordination may be necessary, to ensure that these instruments work as intended in the context of competition policy requirements. 
Where competition policy is not applied or not applied well, markets will often be inefficient and ineffective-resulting in low levels of competition, productivity and economic activity. Such markets usually also display very low levels of innovation. Consumers are charged excessive prices and rent seeking and corruption are usually endemic. Abuse of market power and unnecessary restrictions on competition are a major impediment to the economic progress of many developing countries. The absence of effective competition policy in most developing countries is one of the main reasons why many markets in these countries do not operate as effectively (CUTS International 2007 and Canadian International Development Research Centre 2007).

Competition policy should not be confused with the concept of competitiveness, which relates to the capacity of businesses to be competitive in regional, national and international markets. Competition policy, by fostering the operation of effective and efficient markets, maximizes the wealth-creating potential of business, markets and countries. Competitiveness is about the capacity of individual businesses, sectors of a national economy, regions, or nation states to compete in national and international markets.

Therefore, competition policy is predicated on the view that efficient, effective and competitive markets are the main drivers of economic, productivity and income growth over time. Hence, it is closely linked to the achievement of rising living standards and poverty reduction. Ensuring efficient and competitive markets is particularly important in the dynamic sense-that is, the long-term growth of the economy is crucially dependent on its ability to change and adapt to different consumer preferences and different operating environments. Among the key underpinning factors for efficient, effective and competitive markets are the following:

- firms can enter and leave the market easilyi.e., at limited cost and without unnecessary regulatory impediment;
- firms have incentives to compete vigorously on price, product and service quality and are not impeded by regulation from doing so; and

- dominant firms (those of large size and/or with major strategic advantages) are prevented from acting unfairly and in ways that ultimately substantially reduce competition (e.g., cartels).

In maintaining and encouraging the competitive process, competition policy aims to maximize welfare by ensuring that prices are minimized and that businesses have incentives to invest and earn legitimate profits. Competition policy also seeks to create a business environment conducive to expansion of existing firms and entry of new firms in a market. In most circumstances, if these conditions are met, markets will be "contestable" and usually comprise of effective competition between firms. There will be a high level of innovation in products and services offered. In addition, consumer needs and wants will be met through a range of product type, quality and price combinations. Furthermore, given the social and economic costs of having inefficient and ineffective markets, the gains from properly implementing competition policy are likely to be very large (DFID 2008 and Box 3 for further information). Part five of this paper provides more information about specific aspects of competition policy.

\section{Linking regulatory quality and competition policy}

Both the regulatory quality and the competition policy perspectives should be brought to bear in the development of new and amended regulation. This implies adopting a systematic approach to assessing new regulatory proposals. Recognizing the importance of efficient and effective markets, both the regulatory quality and competition policy perspectives focus on supporting healthy markets and controlling any unnecessary negative 


\section{Box 3: Benefits of Using Competition Policy}

Competition policy generates a range of benefits, including greater productivity and innovation, reduced prices, increased responsiveness to consumers and greater consumer choice. Example: competition policy in Australia is estimated to have increased GDP by 2.5 per cent, increasing household annual incomes by $A \$ 7000$. Specific impacts included reducing average electricity prices by 19 per cent, rail freight charges by between 9 per cent and 42 per cent, and real port charges by 50 per cent. Both RIA and competition policy are a means to an end, including being important drivers of enhanced and strengthened markets and competitiveness. RIA supports the development of high quality competition policy and enhanced competitiveness in Australia (Productivity Commission 2005).

Baker (2003) observes that "the annual welfare benefits from deterring the exercise of market power through antitrust laws as they are enforced today could readily exceed 1 percent of GDP, or $\$ 100$ billion per year," whereas the costs for public and private enforcers are not likely to be greater than $\$ 2$ billion per year in the United States. In addition, Buccirossi et al. (2008) found a positive correlation between antitrust enforcement and Total Factor Productivity in a study for the European Commission (http://ec.europa .eu/economy_finance/events/2008/20081014/Buccirossi.pdf).

market impacts of government interventions in pursuit of important economic, social, environmental, equity or other objectives.

These shared objectives and perspectives imply that there are likely to be benefits in combining, harmonizing or aligning, the two forms of assessment during the process of developing regulations. Potential benefits include:

- avoiding duplication of effort (hence unnecessary use of scarce resources): there is substantial overlap in the issues to be considered in RIA and competition policy assessment, suggesting they should be conducted in an integrated manner; and

- achieving better policy outcomes through better integration of the assessments: better regulatory outcomes are likely if regulatory quality officials and competition policy officials can coordinate their inputs, discuss their particular concerns together and cooperate on ways of improving regulatory proposals.

How these approaches can be best integrated and harmonized are discussed in the following parts of this paper. 


\section{INSTITUTIONS AND PROCESSES FOR IMPLEMENTING REGULATORY QUALITY AND COMPETITION POLICY AGENDAS}

Responsibility for implementing the regulatory quality agenda is usually distributed among a number of institutions across government. This reflects the fact that these disciplines must be adopted at all stages of the policy development process if they are to be fully effective. It also reflects the fact that the regulatory quality agenda is multi-faceted. Responsibility for implementing competition policy is also typically shared among several government bodies. The following discussion summarizes the roles of key institutions within government in relation to both the regulatory quality agenda and competition policy. It particularly highlights ways in which these two perspectives can be brought closer together. A more detailed commentary about the role of different types of institutions is provided in the BRG paper on regulatory institutions.

\section{Roles of regulatory reform and competition authorities - key similarities and differences}

Specialist bodies within government have an essential role to play in ensuring that the regulatory quality and competition policy perspectives are integrated into the work of government. Both competition policy agencies and regulatory reform bodies perform best when they have relatively high levels of independence to perform their respective roles. Almost all OECD countries have established a dedicated regulatory reform authority and a dedicated competition authority (or two or more competition authorities). Competition agencies typically have legal independence and apply competition policy and laws. Regulatory reform agencies also often have a high level of independence and are usually much smaller, often with only a handful of staff, and are based in central agencies or departments which focus on business issues and programs.

The major roles of these organizations are similar in many areas. The following summarizes the roles usually undertaken at present by these authorities and highlights changes that can help to embed competition assessment successfully within the RIA process:

- Advocacy: Both competition and regulatory reform agencies promote awareness of these 
policies and an understanding of their underlying logic and their benefits. They promote the policies within government ministries, to government ministers, business and other stakeholders, and to the wider community.

- Training \& development: Regulatory reform agencies, in particular, train regulatory agency staff in the specific skills needed to conduct regulatory impact assessment. This includes publishing supporting materials on relevant topics. Expanding this training to include the process of competition assessment is a fundamental step. Liaison with competition authority staff can ensure that this training is properly focused and consistent messages are given.

- Assessing proposed regulations: Competition authorities often review draft regulatory proposals and provide feedback to the sponsoring ministry. Similarly, regulatory reform authorities typically review and advise on RIA. Where competition or regulatory concerns remain, these authorities usually provide advice directly to government as part of the Cabinet or other decision-making process. This ability to challenge regulatory proposals is fundamental to ensuring that these bodies have sufficient authority in government to influence outcomes. Where appropriate and feasible, incorporating competition assessments in RIA provides another avenue to help ensure that competition concerns with new regulatory proposals are identified and addressed.

- Policy research: Competition and regulatory reform authorities typically engage in research and monitor developments in these fields, review the actual performance of the policies currently in place, and provide commentary of regulatory issues and trends more broadly.

Where possible and appropriate, regulatory reform authorities should include competition policy perspectives and issues in their work in most of these areas. For example, training materials should emphasize the need to consider competition issues within the broader RIA context, while RIA documents should also highlight relevant competition issues and provide advice on these to government. This should involve consultation between regulatory reform and competition authorities so that consistent messages are provided that fully reflect the competition policy perspective. Such consultation is undertaken routinely in many countries with competition policies and RIA processes and does not in any way impede or undermine their independence or respective roles.

The role of specialist regulatory reform and competition authorities may be particularly important in the context of relatively low government capacities, or where the competition assessment requirement has only recently been added to RIA. While regulatory agencies should be responsible for identifying competition concerns, the competition authority should take the lead in conducting the competition assessment where significant competition policy issues arise. Furthermore, the regulatory reform authority and RIA provide a broader framework for balancing a range of competing public policy objectives, including efficiency, consumer protection, environmental protection and social equity.

\section{Regulatory agencies}

Regulatory agencies that develop proposals and apply existing regulations themselves should bear the primary responsibility for implementing both quality for regulations they administer and/or oversight and their policies that adversely impact on competition.

However, it takes time to reform regulatory agencies to ensure that they are sensitive and capable of delivering better quality regulation. There is a need to change incentives for officials to achieve the necessary cultural change among regulators.

In the short term, the focus of governments should be on ensuring that regulating ministries understand that there is an expectation that they take regulatory quality and competition policy 
perspectives into account in carrying out their tasks. In the longer term, an important objective is to ensure that regulators come to understand the benefits of adopting good practice regulatory policy and administration and are positively motivated to use these approaches as an integral part of their internal regulatory process. This outcome can be facilitated by ensuring that regulatory reform authorities and competition authorities work closely together and share knowledge, information and provide mutual support (as discussed and highlighted in Box 4).

\section{Drafting laws}

Regulations should have a proper legal basis, be communicated effectively and be accessible. Furthermore, the court system should be able to deal effectively and efficiently with legal disputes. A

Box 4: Institutional Responsibilities in the United Kingdom

The United Kingdom recently adopted a competition assessment requirement as part of its RIA process. The competition authority (the Office of Fair Tradingl was made responsible for producing guidelines. It also conducts competition assessments where appropriate and reviews the competition assessments where these are undertaken for new policy proposals that are then included in the RIA documents.

It carried out these responsibilities in conjunction with the regulatory reform authority (the Better Regulation Executive), with a small number of officials working part-time in the BRE in order to develop and promote common and consistent approaches.

UK experience shows that only a small percentage of new regulations require detailed scrutiny. Although about 400 regulations are made each year in the UK, focusing on important high priority and impact regulatory proposals resulted in resources costs being low - only two competition authority officials were required to work on competition assessments.

Source: OECD/DAF/COMP(2007)/7. sound and well-functioning legal system is a vital underpinning for regulatory quality and regulatory institutions.

Law-drafting bodies have the responsibility for ensuring that the legal or juridical quality of regulations is high. This involves a number of dimensions. First, laws must be written in clear and unambiguous style, so that they are readily understood. Second, laws must conform to sound governance standards. For example, all major policy positions and taxes raised should be established in primary legislation, made by the Parliament, with lower level rules (made by ministers or regulatory agencies under delegation from Parliament) dealing only with matters of implementation of already established policy. Other important governance standards are that laws should avoid making the rights of people dependent on administrative decisions, they should not be retrospective in effect and they should incorporate appropriate appeals provisions. Law drafting bodies have an essential role in identifying these legislative quality issues and advocating strongly for high standards in these areas. On the other hand, law drafting bodies are not usually involved in competition policy issues, which are highly specialized in nature and generally outside the scope of their expertise.

\section{Consultation with stakeholders and the community}

When developing regulatory proposals, including competition policy laws, it is very important that the policy development process is transparent and that stakeholders are well-informed and given the opportunity to make a meaningful contribution. Consulting with stakeholders provide a range of benefits, including provision of useful information and feedback. Undertaking a two way dialogue also helps build trust. A well-managed and timely community consultation process can significantly improve regulation-making processes. This is one reason why consultation is a key element of a good practice RIA process. 
It is important to note that consultation takes time and can also generate costs. Therefore, the focus should be on consulting on what the community and key stakeholders consider to be the most important and significant regulatory and competition policy issues.

There are various ways to conduct consultation processes, ranging from public notification of a regulatory proposal through to a comprehensive consultation process undertaken through the various stages of a policy development process. Each approach has advantages and disadvantages and thus should be used on a case-by-case basis. Consultation processes are usually underpinned by government policy, which provides stakeholders with information and certainty about when and how consultation processes will be employed.

\section{The decision-making process within government}

The credibility and effectiveness of RIA and competition assessment is highly dependent on action being taken to ensure that all regulatory proposals forwarded to the Cabinet or other decision-makers comply with relevant policy requirements and standards of analysis. This means that the agency supporting the decision-making process (e.g., the Cabinet Office, or Office of the President) must take a strong role in checking that the relevant analysis accompanies regulatory proposals and, if needed, prevents proposals going forward for consideration until they are accompanied by RIA and competition analysis. Of particular importance is identifying which sectors and/or segments of society are most likely to bear the impacts and costs of the new regulations, the nature and extent of the consultations held and whether there is a "buy-in" by stakeholders into the recommendations being put forward, and that alternative approaches have been fully explored.

Consultation between the regulatory reform and competition authorities is particularly important in this respect. Sound coordination between the specialist agencies responsible for regulatory reform and competition policy and centre of government agencies (i.e., the President/Chief Minister's department and the finance ministry) is essential if a "whole of government" view is to prevail, in terms of achieving the optimum balance between competition policy and other policy objectives. This means that the competition policy perspective must be fully supported by central agencies and appropriate communication maintained in respect of the assessments undertaken. Box 5 provides an example of how this has been structured in Mexico.

\section{Box 5: Strengthening Competitiveness in Mexico}

Mexico experienced a rapid economic transformation and openness in the 1990s, supported by the institutionalization of regulatory and competition policies. Two institutions, technically autonomous from the Ministry of Economy, were set up to conduct reforms in both areas: the Federal Regulatory Improvement Commission (COFEMER) in 2000 following legal amendments and the Federal Competition Commission (CFC) created in 1993. Both institutions have separate mandates and cooperate mainly through opinions expressed by the CFC on impact assessments that are reviewed by the COFEMER

In 2007, the Mexican government designed a new strategy to increase competitiveness of the Mexican economy through the improvement of the regulatory framework, including focusing on competition and regulatory quality. The main purpose of this exercise is to review current legislation in selected economic priority sectors in order to eliminate restrictions to competition and to improve the quality of the regulation by eliminating unnecessary administrative burdens and fine-tuning the current RIA system.

This review process, supported by the Mexican President and with the OECD providing advice, is conducted by Technical Groups of Experts headed by the chairmen of the COFEMER and the CFC. Advisory Groups of Experts in both fields, composed of governmental and external stakeholders, provide input to the work of the Technical Groups. Final decisions are taken by the Cabinet for Economy and Competitiveness, which is part of the Executive. The final recommendations from this reform program will be presented to the Cabinet by 2010 . 


\section{Use of legislation and framework rules}

The main elements of general competition policy are usually expressed in government policy statements and also in competition law. According to the OECD, best practice is that this policy and associated laws should apply as widely as possible throughout the economy. However, specific government regulation can often override the general competition law in particular areas. An important area in the implementation of competition policy is to minimize any exemptions that are inconsistent with the general competition law, in part by ensuring that proposed exemptions are subject to careful scrutiny and alternatives are considered such as applying general competition law.
Regulatory quality principles and regulatory impact analysis requirements are sometimes established in law, but are more commonly set out in policies issued by the executive arm of government, such as head of government (prime minister, president or senior minister). Whichever instrument is used, an explicit requirement that the RIA explicitly address competition issues will help ensure that competition policy issues are developed within the broader RIA context of a balancing of benefits and costs, allowing the adequacy of the competition assessment to be judged along with other issues identified and discussed within the broader RIA document.

As noted above, see the BRG paper on regulatory institutions for a more detailed discussion of their characteristics and roles. 


\section{WHEN IS COMPETITION ASSESSMENT IMPORTANT?}

Most regulatory proposals will not have significant anti-competitive effects and will not require a detailed competition assessment as part of the policy development process. To ensure that competition assessments can be carried out where needed, while minimizing the requirement for competition expertise, a reliable screening process is needed to identify high priority issues. This screening process can be used to identify which regulatory proposals are likely to raise major competition issues that need further careful consideration, while ensuring that unnecessary assessments are not undertaken on other minor regulatory proposals.

In 2007, the OECD published an insightful Competition Assessment Toolkit, which includes such a screening test which has formed the basis of tests employed in a wide range of developed and developing countries. ${ }^{2}$ The OECD screening test is based around three questions that are discussed in further detail below. In short, it suggests that an in-depth competition assessment

2 See: http://www.oecd.org/dataoecd/15/59/39679833 .pdf should be carried out where the regulatory proposal has any of the following three impacts.

\section{Test 1) Limiting the number or range of suppliers}

Reducing the number or range of suppliers or protecting a small number of existing businesses in a market is clearly likely to limit competition, since market power is more likely to be accumulated where markets are less contestable and/or there are few competitors. Regulation is likely to have this effect if it does one or more of the following:

- grants exclusive rights for a supplier to provide goods or services (that is, creates a regulated monopoly);

- establishes a license, permit or authorization process as a requirement of operation (since license conditions are often used to limit entry to the market unnecessarily and protect incumbents from competition); 
- limits the ability of some types of suppliers to provide a good or service (for example, by setting conditions that effectively prevent small businesses from competing);

- significantly raises the cost of entry or exit by a supplier (for example by requiring entrants to demonstrate "financial capacity" or, alternatively, by setting up unduly strict product testing standards); and

- creates a geographical barrier to the ability of companies to supply goods or services, invest capital, or supply labor (for example by limiting access to a market to local suppliers).

\section{Test 2) Limiting ability of suppliers to compete}

Even if there are large numbers of suppliers in a market, competitive pressures may be severely limited if there are regulatory restrictions on their ability to compete with each other. The most commonly found regulatory interventions that are likely to have a substantial effect of this type are the following:

- Regulations that control or substantially influences the prices for goods or services (e.g. by setting maximum or minimum prices, or even determining the exact price to be charged).

- Regulations that limit freedom of suppliers to advertise or market their goods or services. Restrictions on advertising make it more difficult for consumers to obtain information about market offers and reduce their ability to choose the market offer that best suits their needs. This, in turn, reduces the benefits to producers of innovating and providing better market offers.

- Standards for product quality that provide an advantage to some suppliers over others or that are above the level that many well-informed customers would choose. Such provisions prevent consumers from choosing low price/low quality options that they may prefer.

- Significantly higher costs of production for some suppliers relative to others (especially by treating incumbents differently from new entrants).

\section{Test 3) Reducing incentives of suppliers to compete vigorously}

This may be the case if the proposal:

- creates a self-regulatory or co-regulatory regime (since industry-based regulatory arrangements are often used as a means of collusion in the market);

- requires or encourages information on supplier outputs, prices, sales or costs to be published in a manner that facilitates collusion;

- exempts the activity of a particular industry or group of suppliers from the operation of competition policy and law; and

- reduces mobility of customers between suppliers of goods or services by increasing the explicit or implicit costs of changing suppliers.

All these forms of restriction on competition have been used to achieve important public policy goals. However, their negative impact on competition very often outweighs the other benefits they were intended to achieve. There are alternative ways of achieving those benefits in many cases that do not require use of damaging restrictions on competition.

In addition, it is important to add to the OECD screening test explicit reference to regulations not generating significant barriers to businesses operating in the informal sector migrating to the formal sector. This is very important because in developing country contexts, the informal sector 
is usually very large vis-a-vis the formal sector The main direct impact of poor quality regulations and ineffective competition policy is to greatly inhibit businesses in the informal sector registering their business and becoming part of the formal economy, thus paying taxes, following other rules and regulations, etc. Indeed, given the importance of the informal sector in most developing countries, the economic costs of poor quality regulations and ineffective competition policy inhibiting businesses moving to (or operating in) the formal sector will be relatively larger than in the case of developed countries. ${ }^{3}$

3 It must be recognized that the informal sector in developing economies mainly comprises of small, marginal family owned and operated businesses. Even while informal, they add significantly to social economic welfare by generating
Appendix 1 includes a summary table of policy goals that these restrictions are usually used to achieve. It highlights the potential problems such restrictions cause and identifies possible alternative approaches, or safeguards to be applied where they are used. Regulators can use this table to help reduce the extent and/or costs of anti-competitive provisions in their regulatory proposals.

employment, providing various services and promoting entrepreneurship and risk-taking. The incentives for becoming formal and paying taxes, meeting labor standards, adhering to regulated hours of operation, etc., need to be accompanied by an effective and transparent system of regulatory governance. The fear often expressed is that formality also paves the way for local government officials to engage in additional corruption, extract bribes and otherwise harass these businesses. Without proper regulatory governance, these businesses will continue to engage in regulatory avoidance and operate below the radar screeen. 


\section{MECHANISMS FOR COORDINATING COMPETITION POLICY AND REGULATORY QUALITY ASSESSMENTS}

The preceding section provided a screening test that can be used to determine whether a regulatory proposal is likely to raise significant competition issues. Where one or more of the questions included in the screening test is answered positively, a detailed competition assessment should be conducted. Drawing on Section 2's discussion of the broad roles of various bodies within government in relation to regulatory quality and competition assessment, the following mechanisms could be considered as means of coordinating RIA and competition policy assessments of proposed regulations and ensuring that they are carried out efficiently and effectively.

\section{Initial screening}

An easily understood initial screening testalong the lines of the set of questions presented above- should be disseminated by the regulatory reform body as part of the guidelines on the conduct of RIA. The competition and regulatory reform authorities should consult on the development of these guidelines to ensure that competition assessment is effectively integrated with RIA and that the guidelines are consistent with competition policy and enforcement activity generally. The competition authority should provide more detailed guidance material for the use of regulators.

Initial screening, using the test, should be undertaken by the regulatory agency and competition authorities should be available to provide assistance as needed in conducting the screening test. However, such self assessment in practice often does not work, because individual regulators do not have the skills or incentives to correctly identify competition policy issues when developing a regulatory proposal (see Box 6). Therefore, an alternative used in many countries considers requiring all proposed regulations to be reviewed for restrictions on competition by the competition authority and/or the regulatory reform authority.

\section{Detailed competition assessment}

Regulatory agencies are unlikely to have the ability to undertake a detailed competition assessment if screening indicates that such an assessment is 


\section{Box 6: Ensuring Effective Screening of Regulations}

A number of different approaches to screening for competition restrictions have been adopted. These reflect the need to balance the need to ensure that competition issues are reliably identified with the need to avoid unduly burdening the policy process, particularly in the context of relatively limited capacities.

For example, in Mexico, all new secondary legislation likely to affect competition must be reviewed by the competition authority. Korea also requires ministries and government departments to engage in prior consultation with the Korea Fair Trade Commission on regulations that may affect competition. The head of the KFTC holds a Cabinet rank position and sits in on major economic and regulatory policy meetings of the Cabinet.

Hungary's competition authority is required to submit its comments on any regulatory restrictions on competition as part of the Cabinet process. In many countries, consultations among potentially affected ministries are routinely adopted for regulatory proposals. This process can be effective if competition authorities are routinely given the opportunity to contribute. Giving the competition authority discretion about when to engage in this process can ensure that their efforts are appropriately targeted.

In a Report on Competition Advocacy, the ICN indicates that screening of competition-regulatory proposals is most effective when (i) there is early and mandatory (rather than voluntary) consultations; (ii) the competition authority is an autonomous body; (iii) the process is transparent; and (iv) there is a competition culture built through information dissemination, public education, and a vibrant media. In most countries (65 percent) consultation between competition authority and regulators, legislator's et al. is at an early stage and most recommendations put forward are incorporated in regulatory policy decisions.

necessary. Assistance from the competition authority (or, where feasible, other sources of expert advice on competition issues) is important at this point.

The first task is to identify the public policy objective that the competition restriction seeks to achieve. This is essential to allow an assessment of whether the costs of restricting competition may be justified by the benefit to be achieved. Just as importantly, identifying the policy objective is essential to allow alternative means of achieving it to be identified. This enables a judgment to be made about whether the objective can be achieved without restricting competition - or at least by imposing a lesser degree of restriction. Only in this way can the question of whether restricting competition is the best means of achieving the policy goal be answered. This means that regulators and competition experts need to work cooperatively on the assessment.

The need for a comparative approach also means that the assessment needs to be undertaken early in the policy process, before there is a strong commitment to a particular regulatory approach.
The two-part test used in Australia (see Box 8) provides a good basis for these assessments. The key questions include:

- Do the benefits of the restriction on competition outweigh the costs?

- Can the objectives of the regulation only be achieved by restricting competition?

If the objectives of the regulation can be achieved by using an option that does not restrict competition, then this non-restrictive option must be employed.

\section{Review of competition assessment}

In many countries with RIA processes, the regulatory reform authority reviews the RIA document and provides advice on its adequacy. The competition assessment should be considered as part of this process where the regulatory issues under consideration have competition policy impacts or implications. Where major competition issues are involved, the regulatory 
reform authority should be required to consult with the competition authority. This will ensure that appropriate expertise is available and that a consistent approach is taken to competition issues.

Where the restriction on competition contained in a proposed regulation appears to be unjustified, the regulatory reform authority and the competition authority should have the responsibility to argue for a change in the proposed policy, advocating more competition-friendly options to the regulator.

As a general rule, it is best to have a structural separation between the competition authority and regulatory reform authority. Both institutions provide complementary but different roles. The competition authority considers competition policy issues, while the regulatory reform authority oversees the RIA process and ensures that all relevant issues are considered and balanced in a careful and well-informed manner in the RIA.

\section{Advice to decision makers}

If concerns raised by the competition and/or regulatory reform authorities have not been dealt with adequately by the regulator, these bodies should have the responsibility—and the opportunity- to raise these concerns with decision makers.

Ideally, this would include requiring these concerns to be noted in the briefing documents circulated to ministers before Cabinet meetings at which the issues will be decided. At a minimum, these authorities should have the opportunity (and requirement) to brief the ministers to whom they are responsible. In some good practice countries such as Australia, a minister is given explicit responsibility for competition policy, while another minister is responsible for ensuring broader regulatory quality.

\section{Post-implementation review}

Many of the impacts of competition-restricting regulations are either unforeseen or difficult to gauge accurately before a regulation is implemented. One possible addition to competition assessment rules is to require that a post-implementation review be undertaken whenever a regulation with a substantial anti-competitive impact is implemented.

A review undertaken two or three years after a regulation is adopted can allow judgments to be made about whether the benefits expected to flow from the restriction on competition are being achieved. More importantly, it can determine whether the costs have been accurately predicted and whether unanticipated negative effects have arisen that might justify revising or withdrawing the regulation.

Conducting such analysis is not without inherent problems and complexities, due to changes in the business environment and its underlying factors. Moreover, this is an area that is being actively discussed by competition and regulatory authorities in both industrialized and developing countries.

In Costa Rica, a competition assessment was conducted of the government's policy with respect to the rice sector (see Box 7).

\section{Applying competition policy and RIA assessments in developing countries}

Competition policy and RIA assessment can be a demanding and highly technical process. However, such assessments can be undertaken with limited expert resources and, therefore, are feasible even in the context of relatively low-capacity government administrations. That said, it is important to note that RIA is usually implemented in a sequential manner and strengthened progressively over time. Furthermore, RIAs typically focus on a subset of regulation since it is not feasible to prepare RIAs for 


\section{Box 7: Competition Policy, Regulation-Costa Rican Rice Sector}

In 2002, the Costa Rican government enacted regulations to establish CONARROZ, an enterprise with monopoly rights to purchase rice from farmers and to process and distribute it at controlled prices. The stated objectives of CONARROZ include stabilizing domestic rice prices, providing subsidies to farmers to augment output, and increasing productivity through technology transfer.

This has not happened. In fact, a study conducted by the IC of the World Bank Group, in collaboration with the Commission for Pro-Competition (COPROCOM) and the Consumers Association, shows the opposite has occurred. It was found that many small farmers have been driven out of business due to high costs and low profits-in part due to "monopolistic" market power exercised by CONARROZ. In contrast, large-scale rice processing firms have been enjoying windfall profits by vertically integrating backwards into farming, and forward into distribution - while being insulated from international competitive discipline behind import tariff rates of 35 percent. Market concentration has increased with the leading four firms, accounting for market shares of 70 percent. Consumer prices have also increased steadily, and domestic production has decreased by 27 percent. Imports of rice have also increased. Since on average Costa Ricans consume twice the amount of rice as their neighbors, the impact of increased prices is particularly felt by the poor. With this in mind, the study has put forward recommendations for policy changes to promote competition, efficiency and consumer welfare.

This project has allowed consumers, civil society, private sector and some government institutions to question the monopoly rights granted to CONARROZ as well as the policy of regulating the rice market. The study's findings have led to a lively debate and are challenging policymakers to either justify the current system or to dismantle or reconstitute it to better meet the stated objectives. The project points to alternative ways in which Costa Rica can meet its socio-economic-political objectives in respect to this important sector.

Source: Annual Report, IC, the World Bank Group (2006).

all new regulations. Therefore, the extent to which competition policy issues are included within RIA will depend on several factors, such as the type of RIA process used, the type of regulations considered by RIA, as well as the capacities of the country or jurisdiction applying RIA processes.

In some cases, a given regulatory proposal may not require preparation of RIA but will have competition policy implications that should be considered by the competition authority.

In summary, key strategies for applying and developing competition policy and RIA expertise in developing country contexts can include:

- using simple screening tests that focus on identifying the most significant regulations;

- providing training to regulators in competition assessment and RIA;
- ensuring that competition authorities and regulatory reform authorities are kept separate and have clear, mutually supporting and independent roles; and

- providing for a cooperative approach between competition officials, regulatory quality officials, and regulators to identifying possible alternative approaches that do not restrict competition.

Even where full competition and RIA assessments are not possible, the process of systematically seeking to identify restrictions on competition in proposed regulations and considering alternatives that may be less restrictive will yield important benefits. This process will, at a minimum, ensure that policymakers are made aware of the potential harms from competition restrictions and that possible means of avoiding them are brought to their attention (see box 9 on the use of regulation assessments in developing countries). 


\section{Box 8: Integrating Competition Policy and RIA in Australia}

In Australia, state and federal governments signed a set of National Competition Policy Agreements. As part of these agreements, governments agreed to subject all laws to a two-part competition test: restrictions on competition would be adopted or retained only where:

1) Benefits to the society as a whole could be shown to outweigh the costs of the restriction.

2) Benefits could not be achieved in some other way that was less restrictive of competition.

This rule was applied to all existing laws through a legislative review process, resulting in around 1800 Acts being reviewed over a 10-year period. It was also applied to all proposed new laws by integrating the rule with the RIA process. Thus, all RIAs in Australia explicitly assess the proposed laws and regulations in terms of this rule and demonstrate that the proposed laws and/or regulations comply.

These assessments are conducted by the regulators responsible for the rule and are assessed by the regulatory reform authority, along with the rest of the RIA. Where major issues are concerned, the advice of the competition authority is sought to ensure the competition assessment is sound.

\section{Box 9: Integrating Regulation Assessments}

With the advent of trade and investment liberalization, economic de-regulation, and privatization, a large number of developing countries have enacted or strengthened existing laws and policies relating to competition as part of governments economic-legal-regulatory framework. There are approximately 116 countries or jurisdictions with competition legislation - the great majority being developing nations.

A survey by the ICN indicates that 62 percent of the competition agencies were autonomous/independent bodies, and 58 percent participated in the council of ministers or cabinet meetings-a much higher proportions than in developed countries. On the issue of the interface between competition law and sector-specific regulations, the survey reports that 65 percent of the competition agencies are consulted at an early stage in the regulatory policy formulation process, and about 16 percent are involved during the whole process, 12 percent can intervene at any stage, while only 7 percent indicated consultations were at too late a stage. Most successful advocacy has occurred where pro-competition measures have been incorporated in regulatory policies in the telecom, electricity, and transportation sectors, followed by financial, gas distribution, retail trade, and port services.

For example, in Brazil (and in many other countries), the competition authorities successfully countered lobbying by unions of taxi drivers to limit the number of permits or obtain exclusivity rights for passenger traffic to and from domestic airports.

In India, the Competition Commission registered its concerns about a proposal by the Department of Posts \& Telegraphs to extend monopoly control on all letters and packages up to 300 grams, which, had it been adopted, would have ended the growing private courier business.

In Kenya, the Monopolies and Prices Commission, through its enforcement actions, has altered some of the anticompetitive practices in the regulated insurance industry. Also by advocating competitive bidding and eliminating single sourcing practices in government procurement, significant reductions in prices of drugs and hospital supplies, school uniforms and text books, and road transportations services have taken place. Similar examples of positive benefits of injecting competition principles in other developing and transition economies have been reported from countries such as Argentina and Zambia. 
If this approach is adopted, the required standards of the competition assessments and RIA can be increased progressively over time as skills develop and resources expand. This highlights the importance of a practical approach to implementation and also means concrete benefits-in terms of better quality regulation and regulatory governance-will be available to developing countries without the need for a large call on resources. 


\section{APPENDIX I: OPTIONS FOR ADDRESSING REGULATORY RESTRICTIONS}

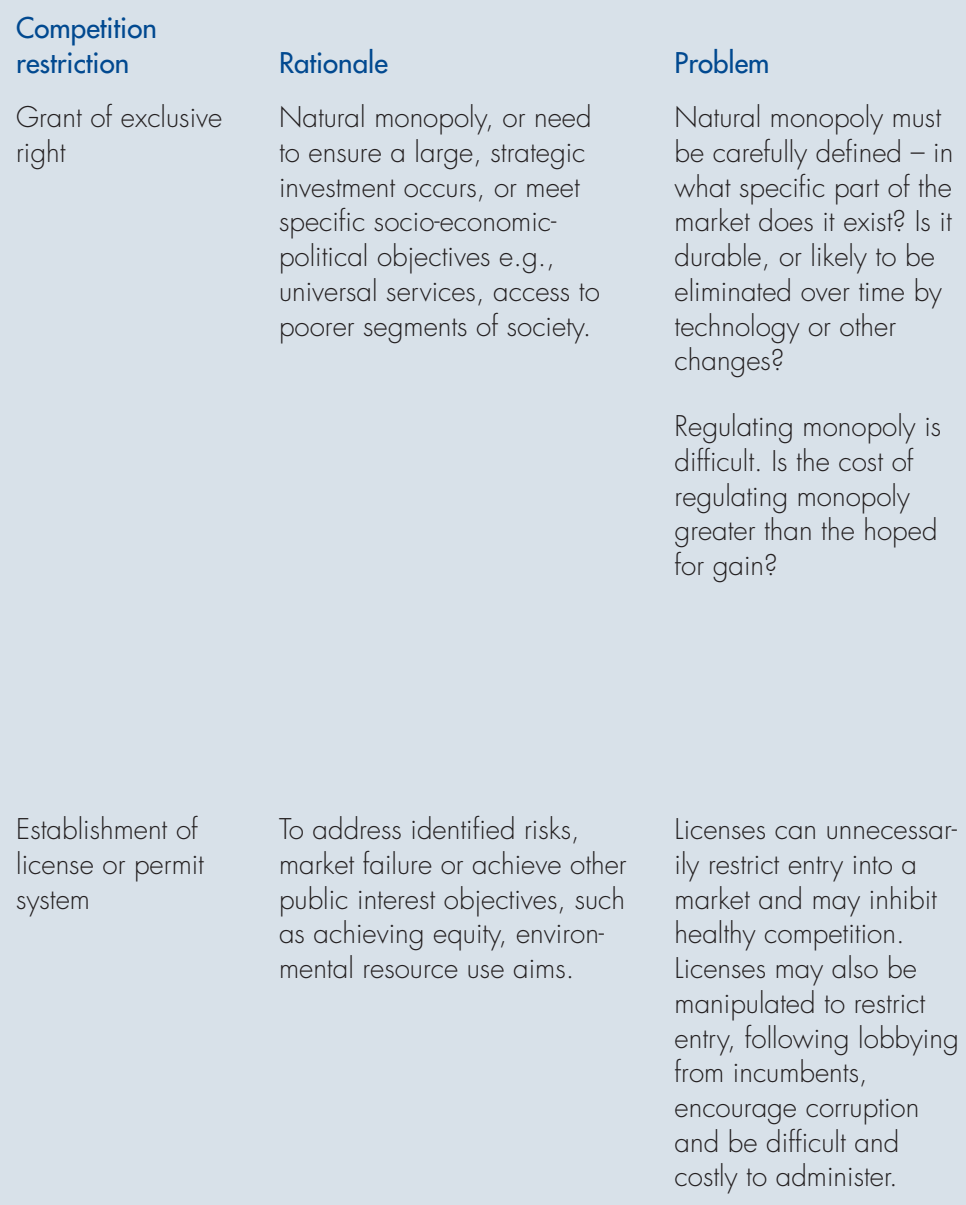

Establishment of license or permit system

To address identified risks, market failure or achieve other public interest objectives, such as achieving equity, environmental resource use aims.

Licenses can unnecessarily restrict entry into a market and may inhibit healthy competition. Licenses may also be manipulated to restrict entry, following lobbying from incumbents, encourage corruption and be difficult and costly to administer.

\section{Alternative policy approach}

Careful allocation of monopoly right, involving:

- Limiting its scope

- Limiting its duration

- Auctioning the monopoly right

- Repeating the auction periodically.

Consider alternative means of promoting investment?

Considering other more direct ways to help target groups, sectors and regions.

Break up monopoly and encourage competition in areas not characterized by natural monopoly (such as electricity generation and distribution) and focus regulation on the core natural monopoly

(e.g. electricity transmission)

Review license to ensure that the benefits of regulation exceed the costs.

Consider alternatives to licenses, such as on relying on existing regulations, fiscal instruments, information campaigns, marketbased instruments, products liability laws or quasi-regulation (such as industry codes of conduct).

Where licenses and permits are used, explore scope to minimize their anti-competitive impacts. 


\section{Competition restriction}

Limits on ability of suppliers to provide a good or service

Raising the cost of entry or exit

Restricting the flow of goods, services, capital or labor across borders

\section{Rationale}

Often a deliberate attempt in procurement policies to favor local (regional) business, or to favor small business or to promote domestic enterprise/ import substitution.

Often a consumer protection rationale, with raised entry costs due to increased product testing requirements, financial capacity (including insurance) requirements, etc.

Often a tool of regional policy, attempting to enhance the viability of regional economies, increase employment, etc.
Controls on prices of goods or services

Restrictions on advertising

Setting product standards at high levels
Maximum prices often a corollary of entry restrictions. Minimum prices sometimes a response to concerns over "predatory pricing" where price competition has been fierce.

Often intended to prevent false/misleading advertising or to discourage "over-consumption" where this can result in negative impacts on consumers, or some profession's view advertising as de-meaning or creating barriers to entry.

Standards may be set above levels informed consumers would choose to minimize political risks or provide a level of protection considered desirable at the political or broader community level.

\section{Problem}

Such policies are generally protectionist.

Cost to procurers is high Other means of favoring particular groups likely to be more effective and transparent.

Policies particularly disadvantage new entrants, protecting incumbents and reducing innovation \& dynamism in the market.

Many provisions actually produce relatively limited consumer benefits.

Artificially reduces the size of the market. Often significant efficiency costs are created by excluding potentially larger and efficient groups of alternative suppliers. Invites retaliatory action from other governments - a "negative sum" game.

Normal market disciplines are defeated, protecting inefficient producers. Consumers suffer higher prices. Even maximum prices may tend to increase average prices by serving as a price signal.

\section{Restricting advertising} limits consumer information and makes markets less efficient. It is usually ineffective as a means of limiting consumption or choice, or limiting entry.

Setting high standards limits consumer choice, especially ability to choose low price/low quality options. Likely to be a particular problem for poorer consumers.

\section{Alternative policy approach}

Careful consideration needed of the policy merits of favoring particular groups. If

warranted, consider subsidies or vouchers or targeted removal of unwarranted impediments (regulatory or otherwise) to participation.

Assess extent of consumer problems/potential harms and size of benefits due to these interventions.

Keep requirements to a minimum level.

Consider consumer education provisions as an alternative.

Other regional policy tools include provision of subsidies, targeted investments by government, enhancing infrastructure, etc.
General competition law can deal with predatory pricing, which is in any case rare. Where entry restrictions lead to monopoly power, a better solution is often to remove these restrictions. There are virtually no cases in which regulation of prices is a "first best" solution.

Rely on general competition law to prevent "false and misleading" advertising.

Competition laws allow for cooperation in setting standards if not used to unduly limit competition; emphasis should be placed on performance vs. technical standards. 


\section{BIBLIOGRAPHY}

Ahn, S. (2002). "Competition, innovation and productivity growth: a review of theory and evidence." OECD Economics Department Working Paper No. 317, www.oecd.org.

Baker, J.B. (2003). The case for antitrust enforcement, Vol. 17, Nr. 4. Journal of Economic Perspectives, 27.

Better Regulation Commission (2006). Annual Report 2006, London (www.brc.gov.uk).

Canadian International Development Research Centre 2007, Competition Law in Action - Experiences from developing countries, Ottawa.

Conway, P., De Rosa,D., Nicoletti, G., and Steiner, F. (2006). "Regulation, Competition and Productivity Convergence." OECD Economics Department Working Paper No 509. www.oecd.org.

Cook, P. (2001). "Competition and its regulation: key issues," Centre on Regulation and Competition Working Paper No. 2, Manchester (www.competition-regulation.org.uk).
Cook, P and Mosedale, S. (eds.) (2007). Regulation, Markets and Poverty, Cheltenham: Edward Elgar.

CUTS International 2007. Politics Trumps Economics - Lessons and experiences on competition and regulatory regimes from developing countries, Jaipur.

Department for International Development (DFID) 2008. Competition Assessment Framework - An operational guide for identifying barriers to competition in developing countries, DFID, London, January.

Evenett, S. (2005). "What is the relationship between competition law and policy and economic development?" in Competition Policy and Development in Asia, Basingstoke: Palgrave Macmillan.

Freeman, P. "Regulation and Competition Chalk and Cheese?" Speech, May 2006, London: Competition Commission (www.competitioncommission.org.uk).

FIAS (foreign Investment Advisory Services) Annual Report 2006, The World Bank Group, Washington D.C. 
Hylton, K and F. Deng 2007.Antitrust Around the World: An Empirical Analysis of the Scope of Competition Laws and their Effects, Antitrust Law Journal.

ICN (International Competition Network). "Advocacy and Competition Policy" ICN Conference, Naples, 2002 (www.internationalcompetitionnnetwork.org).

Jordana, J and Levi-Faur, D. (2004). The Politics of Regulation: Institutions and Regulatory Reforms for the Age of Governance. Cheltenham: Edward Elgar.

Khemani, R. 2007. "Competition Policy and Promotion of Investment, Economic Growth and Poverty Alleviation in Least Developed Countries." Occasional paper 19, FIAS/The World Bank Group, Washington D.C.

Littlechild, S. (2002). "Regulators, competition and transitional price controls: a critique of price restraints in electricity supply and mobile telephones." London: Institute of Economic Affairs, www.iea.org.uk.

McLean, I (2004). "The history of regulation in the United Kingdom: three case studies in search of a theory" in The Politics of Regulation: Institutions and Regulatory Reforms in the Age of Governance, Cheltenham: Edward Elgar.

Newberry, S (2006). "The relationship between regulation and competition policy for network industries," University of Cambridge Electricity
Policy Research Group, Working Paper EPRG0611, www.electricitypolicy.org.uk.

Nicoletti, G. and Scarpetta, S. (2005). "Regulation and Economic Performance: Product Market Reforms and Productivity in the OECD." OECD Economics Department Working Paper No. 460, www.oecd.org.

Nicoletti, G. and Scarpetta, S. (2003). "Regulation, productivity and growth." OECD Economics Department Working Paper No. 347, www .oecd.org.

Ogus, A. (2001). "Regulatory Institutions and Structures." Centre on Regulation and Competition Working Paper No 4, Manchester (www. competition-regulation.org.uk).

Ogus, A. (2004). "W(h)ither the economic theory of regulation? What economic theory of regulation?" in The Politics of Regulation: Institutions and Regulatory Reforms for the Age of Governance, Cheltenham: Edward Elgar.

Parker, D. (2001). "Economic regulation: a preliminary literature review and summary of research questions arising." Centre on Regulation and Competition Working Paper No 6, Manchester. (www.competition-regulation.org.uk).

Scarpetta, S. and Tressel, T (2002). "Productivity and convergence in a panel of OECD industries: Do regulations and industries matter?" OECD Economics Department Working Paper No. 342, www.oecd.org. 


\section{ANNEX: BETTER REGULATION FOR GROWTH PROGRAM}

The Better Regulation for Growth (BRG) Program was launched in 2007 by the Dutch Ministry of Foreign Affairs, the UK Department for International Development (DFID) and IC, the investment climate advisory service of the World Bank Group.

The objective of the BRG is to improve the regulatory and investment climate in developing countries, thereby stimulating private sector investment, economic growth and poverty reduction. The BRG program aims to achieve this by developing and disseminating for the first time widely practical and operational guidance that will help developing countries design and implement effective regulatory reform programs.
The BRG Program has resulted in preparation of eight thematic papers on regulatory governance issues, covering a broad spectrum: from regulatory governance, links to competition policy, regulatory institutions and tools to indicators for regulatory quality. It has also involved preparation of five country case studies on regulatory capacities in selected African countries.

The web portal www.ifc.org/brg is part of the BRG Program and contains key documents, including references extracted from a comprehensive compendium of resources on regulatory management and reform and a newly developed RIA database. 